OPEN ACCESS

Edited by: Johnny Padulo,

University eCampus, Italy

Reviewed by:

Marianna Alesi,

Università di Palermo, Italy

Marco Cavallo,

eCampus University, Italy

*Correspondence:

Olivia K. Faull

olivia.faull@ndcn.ox.ac.uk

Specialty section:

This article was submitted to

Exercise Physiology,

a section of the journal

Frontiers in Physiology

Received: 29 April 2016 Accepted: 30 May 2016

Published: 16 June 2016

Citation:

Faull OK, Cox PJ and Pattinson KTS

(2016) Psychophysical Differences in

Ventilatory Awareness and

Breathlessness between Athletes and

Sedentary Individuals.

Front. Physiol. 7:231

doi: 10.3389/fphys.2016.00231

\section{Psychophysical Differences in Ventilatory Awareness and Breathlessness between Athletes and Sedentary Individuals}

\author{
Olivia K. Faull ${ }^{1,2 *}$, Pete J. Cox ${ }^{2}$ and Kyle T. S. Pattinson ${ }^{1}$ \\ ${ }^{1}$ FMRIB Centre and Nuffield Division of Anesthetics, Nuffield Department of Clinical Neurosciences, University of Oxford, \\ Oxford, UK, ${ }^{2}$ Department of Physiology, Anatomy and Genetics, University of Oxford, Oxford, UK
}

Purpose: Breathlessness is a complex set of symptoms that are comprised of both sensory and affective (emotional) dimensions. While ventilation is now understood to be a potential limiter to performance in highly-trained individuals, the contribution of breathlessness-anxiety in those nearing maximal ventilation during intense exercise has not yet been considered as a limiter to performance.

Methods: In this study, we compared the physiology and psychology of breathlessness in 20 endurance athletes with 20 untrained age- and sex-matched sedentary controls. Subjects completed baseline spirometry and anxiety questionnaires, an incremental exercise test to exhaustion and a steady-state hypercapnic ventilatory response test, with concurrent measures of breathlessness intensity and breathlessness-anxiety.

Results: Compared with sedentary subjects, athletes reported equivalent breathlessness intensity but greater breathlessness-anxiety at maximal exercise (athletes vs. sedentary (mean \pm SD): breathlessness intensity (0-100\%) 80.7 (22.7) vs. 72.5 (17.2), $p=0.21$; breathlessness-anxiety (0-100\%), 45.3 (36.3) vs. 22.3 (20.0), $p=0.02)$. Athletes operated at higher proportions of their maximal ventilatory capacity (MV) (athletes vs. sedentary (mean ventilation \pm SD; \% MV): 101.6 (27.2) vs. 73.7 (30.1), $p=0.003$ ). In the athletes there was a positive linear correlation between ventilation and breathlessness score during the hypercapnic challenge that was not observed in the sedentary controls.

Conclusion: The results of this study indicate that whilst operating at high proportions of maximal ventilation, breathlessness-anxiety becomes increasingly prominent in athletes. Our results suggest that ventilatory perception pathways may be a target for improved athletic performance in some individuals.

Keywords: breathlessness, anxiety, ventilation, athletes, maximal exercise

\section{INTRODUCTION}

Breathlessness is the frightening sensation of not getting enough air. A recent model of breathlessness describes multiple sensory dimensions that include work/effort, air hunger and chest tightness (Schwartzstein et al., 1990; Lansing et al., 2000, 2009). As discussed by Lansing et al. (2009), breathlessness has both sensory components (often related to the strength or intensity of 
the sensation) and affective or emotional components that relate to how unpleasant or worrying the sensation feels, and to the resulting associated anxiety (termed breathlessness-anxiety in this paper). These sensory and affective components may operate independently in the face of changes in ventilation (von Leupoldt and Dahme, 2005; Banzett et al., 2008).

Several medical conditions, such as chronic obstructive pulmonary disease (COPD), cardiac disease, cancer (Solano et al., 2006), and panic disorder (Smoller et al., 1996), are commonly associated with debilitating and frightening breathlessness. Breathlessness is well-described in motor neurone disease (Georges et al., 2016; Pattinson and Turner, 2016), and it is occasionally described in other neurological and neuromuscular conditions including Parkinson's disease (Bayulkem and Lopez, 2010), Multiple Sclerosis (Mutluay et al., 2005), and muscular dystrophy (Sivak et al., 1999). Often symptoms relate poorly to objective physiological measures of disease severity, such as spirometry (Jones, 2001; Herigstad et al., 2015). Functional brain imaging is beginning to reveal the brain mechanisms by which affective and emotional processes contribute to breathlessness (Herigstad et al., 2011, 2015; Hayen et al., 2013) and how peripheral respiratory input is integrated with higher consciousness (Ezra et al., 2015; Faull et al., 2015, 2016).

In healthy individuals, moderate to severe breathlessness is well-recognized as a normal sensation during intense exercise (Simon et al., 1989; Hamilton et al., 1996; Borg et al., 2010). These breathlessness sensations are usually considered "nonthreatening" due to precise matching between expectation and the actual ventilatory response to heavy exercise (Laviolette and Laveneziana, 2014). However, as evidence continues to accumulate for the performance-limiting capacity of the ventilatory system in athletes (Powers et al., 1988; Johnson et al., 1992; Harms et al., 1997, 2000), it is possible that the affective components of breathlessness and the resultant anxiety when nearing maximal ventilation may become a key factor within the complex limitations of athletic performance in highly-trained individuals.

Ventilation during exercise is tightly controlled. A balance of neurally-modulated feed forward ventilatory commands and peripheral feedback stimulate increased ventilation that initially corresponds with exercise intensity (Kaufman and Forster, 1996; Waldrop et al., 1996). As exercise intensity increases, flux through the mitochondrial tricarboxylic-acid (TCA) cycle increases to match increased energy demands, increasing production of carbon dioxide $\left(\dot{\mathrm{VCO}}_{2}\right)$ (Wasserman et al., 1967). This linear relationship between exercise intensity and $\dot{\mathrm{VCO}}_{2}$ continues until the anaerobic threshold, where $\dot{\mathrm{VCO}}_{2}$ (and hence ventilation) increases disproportionately to the rate of oxygen consumed $\left(\dot{\mathrm{VO}}_{2}\right)$ and exercise intensity (Wasserman et al., 1973; Beaver et al., 1986). Deviation from this linear trend is currently understood to be due to the additional involvement of anaerobic metabolism, with increased respiration allowing buffering of lactic acid by $\mathrm{HCO}_{3}^{-}$ions that are excreted by the lungs as $\mathrm{CO}_{2}$ (Wasserman et al., 1973; Beaver et al., 1986).

During maximal exercise, the ability to "over-ventilate" beyond our metabolic needs maintains arterial-oxygen saturation (for exercising at sea level) in the majority of individuals, and thus ventilation itself was originally not considered a limiting factor to exercise performance (Bassett and Howley, 2000; McArdle et al., 2006). However, evidence now exists for both mechanical limitations of the lungs and respiratory muscles for inadequate alveolar ventilation in many elite athletes (Dempsey et al., 1984; Powers et al., 1988; Johnson et al., 1992), and a significant effect of respiratory muscle work on cardiac output to compromise peripheral muscle blood flow and exercise performance (Harms et al., 1997, 2000).

Alternatively, exertional breathlessness (although likely to be vastly more complex than in healthy individuals) can be induced even at very low intensities of exercise in people with respiratory disease, such as seen in COPD (Aldrich et al., 1982). Although maximal ventilation is impaired in COPD, the affective response to breathlessness at even low work rates has powerful limiting effects on performance. Particularly important is the breathlessness-related anxiety that is thought to drive behavioral changes and exacerbate symptoms, causing these individuals to cease exercising well before any significant ventilatory distress (Lansing et al., 2009; Herigstad et al., 2011, 2015; Janssens et al., 2011; Hayen et al., 2013). Therefore, if breathlessness-related anxiety can severely limit exercise performance in people with respiratory disease (Carrieri-Kohlman et al., 2001, 2010; Janssens et al., 2011), it seems plausible that highly-trained athletes who are capable of reaching maximal ventilory capacity during heavy exercise may also be affected by breathlessness-anxiety, albeit at much higher work rates, potentially contributing to performance limitations.

In this study, we examined whether endurance exercisetrained athletes differed in their intensity perception and anxiety of breathlessness during exercise compared with sedentary controls. Additionally, we employed a hypercapnic ventilatory response test to investigate whether the perceptual response to chemostimulated ventilation differed between the groups independent of exercise. Due to the importance of breathlessness-anxiety in determining exercise performance in people with clinical breathlessness, we hypothesized that athletes (who are known to operate at higher ventilatory capacities) may also present with greater breathlessness-anxiety during maximal exercise than sedentary controls. Understanding the relative contributions of both sensory and affective components of exercise-induced breathlessness may reveal a role of breathlessness-anxiety in athletic performance; an idea that has currently been overlooked in the current literature.

\section{MATERIALS AND METHODS}

\section{Subjects}

The Oxfordshire Clinical Research Ethics Committee approved the study and volunteers gave written, informed consent. In this study, we compared 20 endurance athletes and 20 age- and sexmatched sedentary subjects (20 males, 20 females; mean age \pm SD, $26 \pm 7$ years; age-matched \pm 2 years) in a cross-sectional design. The athlete group consisted of subjects who participated in endurance exercise training five or more times per week (cycling, rowing, distance running), while the sedentary group comprised subjects who were not involved in any organized 
exercise, and minimal commuting exercise. One athlete subject did not complete the maximal exercise test due to injury.

\section{Questionnaires}

Due to the cross-sectional nature of this experiment, a thorough baseline comparison of general mood and anxiety between the two groups was necessitated, to assess any potential psychological influences on the ventilatory perceptions measured throughout the experiment. Self-report questionnaires were employed to assess any underlying differences in general trait anxiety, mood/depression or anxiety of bodily sensations. The questionnaires consisted of:

- Spielberger State-Trait Anxiety Inventory (STAI; Spielberger, 2010)

- Anxiety Sensitivity Index (ASI; Reiss et al., 1986)

- The Centre for Epidemiologic Studies Depression Scale (CESD; Radloff, 1977)

Subjects were also asked to record how many hours of physical activity they typically completed per week, the intensity of the exercise (easy, moderate or intense) and what types of exercise they performed. They were asked to recall and record their last week of exercising activity.

\section{Visual Analog Scales for Breathlessness and Breathlessness-Anxiety}

Breathlessness and breathlessness-related anxiety were also measured during changes in ventilation associated with chemostimulated breathing and incremental exercise (outlined below). During both protocols, rating scores of breathlessness ("How breathless are you?") were recorded at rest and after each stage, using a visual-analog scale (VAS) between "Not at all breathless" (0\%) and "Most intense breathlessness imaginable" $(100 \%)$. Subjects were also asked to rate how anxious they were about their breathing ("How anxious are you about your breathing?"), using a VAS between "Not at all anxious" (0\%) and "Extremely anxious" (100\%) immediately following the breathlessness scale at each stage.

\section{Spirometry}

Spirometry was used to asses lung capacity and function, and was performed according to the Association for Respiratory Technology and Physiology standards (Levy et al., 2009). A full inspiration and expiration was used to measure forced vital capacity (FVC) of the lungs using three attempts, according to established guidelines (Levy et al., 2009). Maximal voluntary ventilation (MVV) was also tested to assess each subject's ability to ventilate of their own volition, where subjects were asked to ventilate maximally through the mouthpiece and turbine for $10 \mathrm{~s}$. The best of two MVV measurements was recorded. Spirometry measurements were recorded using a mouth-piece (Hans Rudolf, Kansas City, MO, USA) and turbine connected to gas and flow analyser (Cortex Metalyser 3B, Cranlea Human Performance Ltd, Birmingham, UK), and subjects wore a nose clip for all spirometry tests. Metasoft studio software (Cortex, Versions 3.9.9 and 4.9.0, Cranlea Human Performance Ltd) was used to calculate all spirometry measurements.

\section{Breathlessness Response to Chemostimulated Ventilation}

In this study we measured the ventilatory and subjective responses to a hypercapnic challenge, to better characterize any perceptual differences in ventilation between the groups. We maintained partial pressure of end-tidal oxygen $\left(\mathrm{P}_{\mathrm{ET}} \mathrm{O}_{2}\right)$ at resting levels by manually controlling the fraction of inspired oxygen in the gas mixture as ventilation increased. To administer the hypercapnic stimulus, a breathing system was designed to administer adjustable quantities of humidified medical air, carbon dioxide $\left(\mathrm{CO}_{2}\right)$ and oxygen $\left(\mathrm{O}_{2}\right)$, and gas sampling was displayed on a computer (using Labchart 7; ADInstruments Ltd, Oxford, United Kingdom) to monitor expired gases at all times (Figure 1). Expired gases were determined using a rapidly-responding gas analyser (Gas Analyser; ADInstruments Ltd, Oxford, United Kingdom), and ventilatory flow and volume were determined using a pneumotachograph (ADInstruments Ltd).

Subjects were positioned supine and attached to the breathing system. Eight minutes of resting breathing was initially recorded, with subjects rating their breathlessness and breathlessnessanxiety every $4 \mathrm{~min}$ using a VAS (explained above) presented on a computer screen and controlled by the participant via a button box. Resting values of $\mathrm{P}_{\mathrm{ET}} \mathrm{CO}_{2}$ and $\mathrm{P}_{\mathrm{ET}} \mathrm{O}_{2}$ were

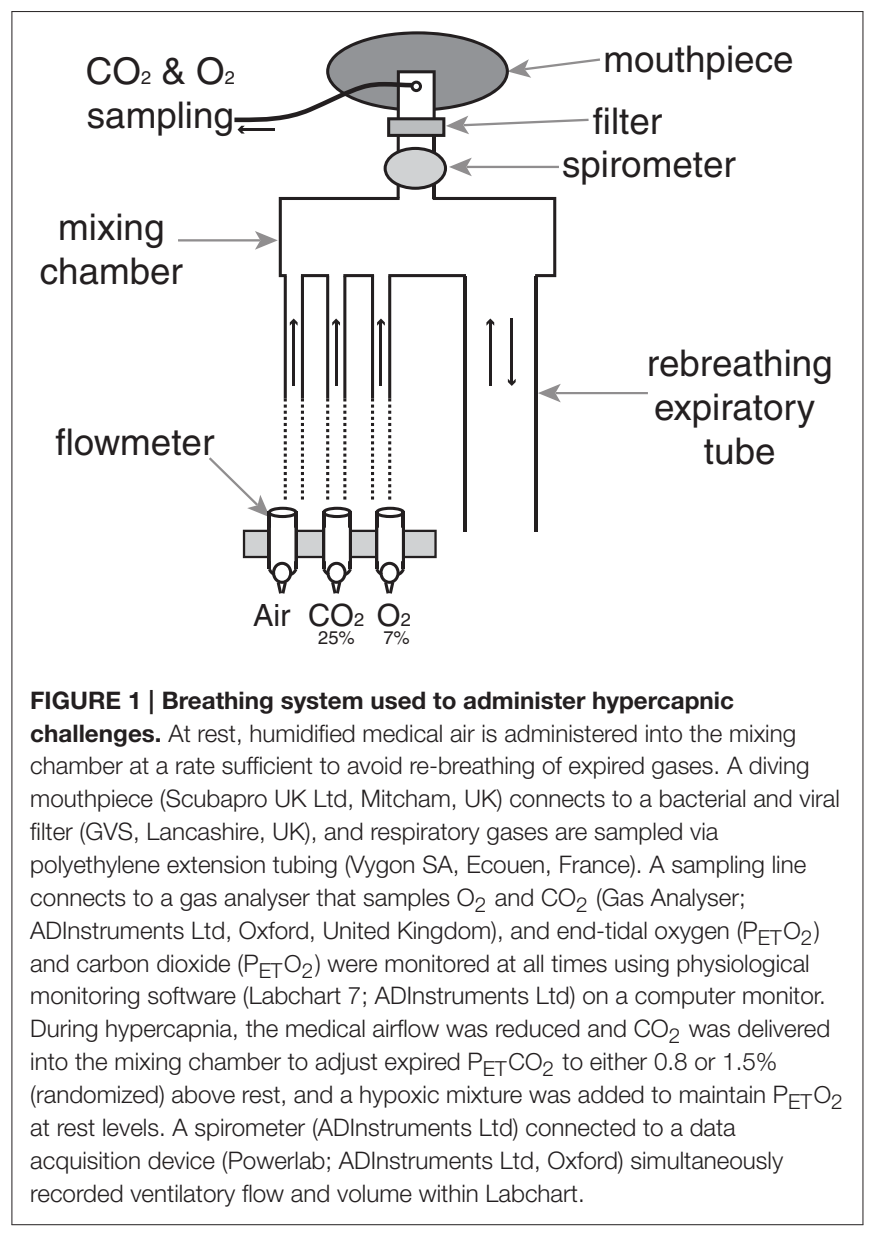


determined during this baseline period, before two levels of hypercapnia were administered. The hypercapnic periods involved a 3 min elevation in $\mathrm{P}_{\mathrm{ET}} \mathrm{CO}_{2}$ of $0.8(6.1 \mathrm{~mm} \mathrm{Hg})$ and $1.5 \%$ (11.2 $\mathrm{mm} \mathrm{Hg}$ ) above baseline (randomized order, separated by 4 min of breathing medical air) whilst $\mathrm{P}_{\mathrm{ET}} \mathrm{O}_{2}$ was maintained at resting levels throughout the experiment (isooxia) through adjusting the concentration of oxygen in the inspired gas mixture, by carefully titrating appropriate amounts of a hypoxic gas $\left(7 \% \mathrm{O}_{2}\right.$, balance nitrogen) into the inspirate according to individual subject's requirement. A final 4 min of breathing medical air followed the second hypercapnic stimulus to finish the test. Subjects were asked to rate their breathlessness and anxiety at the end of each block of hypercapnia and medical air. Hypercapnic ventilatory response was also calculated for each subject by regressing $\mathrm{P}_{\mathrm{ET}} \mathrm{CO}_{2}$ values at rest and during the two levels of hypercapnia against the corresponding ventilations.

\section{Breathlessness Response to Exercise Stimulated Ventilation}

To assess any possible changes in breathlessness perception as a result of exercise, subjects lastly performed an incremental submaximal to maximal exercise test with concurrent ventilatory and breathlessness measures. A relative sub-maximal point of reference of the "anaerobic threshold" was used for comparison between the two groups, as well as maximal exercise measures.

The incremental exercise test to exhaustion was completed on a stationary bicycle (Ergoline 500, Lindenstrasse, Germany), with subjects seated in a comfortable, upright position on standard handlebars. A facemask (Hans Rudolf) and turbine were connected to a gas and flow analyser (Cortex Metalyser 3B, Cranlea Human Performance Ltd; McLaughlin et al., 2001) to measure expired gases and ventilatory flow on a breathby-breath basis, with a pneumotach sampling rate exceeding $500 \mathrm{~Hz}$ (output averaged over $15 \mathrm{~s}$; Metasoft studio software, Cortex, Versions 3.9.9 and 4.9.0, Cranlea Human Performance Ltd). Exercise began between 50 and $150 \mathrm{~W}$ (depending on predicted $\dot{\mathrm{VO}}_{2 \text { peak }}$ ) at a self-selected cadence (target of 90 $\mathrm{rpm}$ ), and $3 \mathrm{~min}$ stages of $50 \mathrm{~W}$ increments were completed until exhaustion. These stages were chosen to allow steadystate assessment of breathlessness at each exercise intensity. Breathlessness and breathlessness-anxiety were rated on a $0-$ $100 \%$ VAS scale (as described above) at the beginning of the exercise test, in the last $30 \mathrm{~s}$ of each stage and at exhaustion. Anaerobic threshold was determined by visual inspection using the V-slope method (Wasserman et al., 1973; Beaver et al., 1986).

\section{Statistics}

All data are presented as means \pm standard deviation. Statistical analysis was performed using SPSS (Version 21, SPSS, IBM, Armonk, New York, USA), and statistical significance was established a-priori at $p<0.05$ using a Student's independent (unpaired) samples $t$-test.
TABLE 1 | Mean \pm SD baseline group physiology measures and questionnaires.

\begin{tabular}{lccc}
\hline & Athlete & Sedentary & \\
\hline Females/Males & $10 / 10$ & $10 / 10$ & \\
Training volume (hours/week) & $11.5(0.7)$ & 0 & \\
Age (years) & $25.8(7.5)$ & $25.7(7.4)$ & $p=0.95$ \\
Height (m) & $1.8(0.9)$ & $1.7(0.1)$ & $p=0.01^{*}$ \\
Weight (kg) & $75.2(10.1)$ & $68.7(13.6)$ & $p=0.09$ \\
BMI (kg/m2) & $23.1(2.8)$ & $23.3(3.5)$ & $p=0.87$ \\
FVC (L) & $5.7(0.9)$ & $4.2(1.2)$ & $p<0.001^{*}$ \\
FVC (\% predicted) & $109.5(9.4)$ & $91.0(19.5)$ & $p<0.001^{*}$ \\
FEV1/FVC (\%) & $78.2(7.0)$ & $81.3(4.6)$ & $p=0.10$ \\
MW (L/min) & $150.9(42.8)$ & $113.0(39.5)$ & $p=0.01^{*}$ \\
Exercise (volume x intensity) & $20.3(6.0)$ & $1.8(1.9)$ & $p=0.001^{*}$ \\
Trait anxiety & $29.6(5.9)$ & $30.8(6.8)$ & $p=0.54$ \\
Pre-exercise state anxiety & $27.8(6.5)$ & $25.6(5.4)$ & $p=0.25$ \\
Anxiety sensitivity index & $13.5(6.1)$ & $16.1(7.7)$ & $p=0.24$ \\
Depression & $6.4(4.2)$ & $7.6(4.7)$ & $p=0.40$ \\
\hline
\end{tabular}

BMI, body mass index; FVC, forced vital capacity; FEV1/FVC, forced expiratory volume in $1 s$ as a fraction of forced vital capacity; MVV, maximal voluntary ventilation. Exercise exposure ("Exercise") was measured as the number of hours per week $x$ intensity of exercise (1-3: easy, moderate, intense). *Significantly different $(p<0.05)$ between groups.

\section{RESULTS}

\section{Baseline Physiology and Psychology}

All physiological and psychological baseline measures are presented in Table 1. Athletes were significantly taller, with larger lung vital capacities and MVV. No differences were observed between the groups for any baseline psychological measures.

\section{Breathlessness Response to Exercise Stimulated Ventilation}

A summary of the physiological and psychological variables measured during incremental exercise is presented in Table 2. As expected, both work rate and $\mathrm{VO}_{2}$ were greater in athletes at both anaerobic threshold and maximal exercise, and the anaerobic threshold of athletes was at a greater percentage of their maximum. At maximal exercise, the absolute and relative increase in ventilation from baseline was greater in athletes, and peak volume of oxygen consumption $\left(\mathrm{VO}_{2 \text { peak }}\right)$ was larger in the athlete group. At maximal exercise, athletes ventilated at a greater proportion of their MVV than their sedentary counterparts. For the psychological variables, while there was no difference in breathlessness intensity values at maximal exercise between the groups, athletes rated significantly higher in breathlessness-anxiety than sedentary subjects (Figure 2). Further investigation revealed that breathlessness-anxiety at maximal exercise positively correlated with measured $\mathrm{VO}_{2 \text { peak }}$, while breathlessness intensity did not (Figure 3). A post-hoc power calculation was performed to provide an initial estimation of the effect size in this pilot study, and produced a $d_{\text {cohen }}=$ 0.79 for differences in breathlessness-anxiety at maximal exercise, falling just below the conventional "large" effect size threshold (Cohen, 1992). 
TABLE 2 | Physiological and psychological variables during rest and incremental exercise test to exhaustion on a cycle ergometer (mean \pm SD).

\begin{tabular}{|c|c|c|c|}
\hline Anaerobic threshold & Athlete & Sedentary & \\
\hline Work rate $(\mathrm{W})$ & 219.7 (46.8) & $102.6(24.9)$ & $p<0.001^{*}$ \\
\hline Work rate (\% of max) & $67.6(7.7)$ & $59.7(12.8)$ & $p=0.03^{*}$ \\
\hline$\dot{\mathrm{V}} \mathrm{O}_{2}(\mathrm{~mL} / \mathrm{kg} / \mathrm{min})$ & $38.4(7.7)$ & $20.3(4.5)$ & $p<0.001^{*}$ \\
\hline$\dot{\mathrm{V}}_{\mathrm{E}}(\llcorner/ \mathrm{min})$ & $76.7(17.0)$ & $38.9(10.1)$ & $p<0.001^{*}$ \\
\hline$\dot{\mathrm{V}}_{\mathrm{E}}(\%$ of $\max )$ & $53.4(10.0)$ & $52.6(13.3)$ & $p=0.84$ \\
\hline Breathlessness intensity (\%) & $22.9(17.1)$ & $16.1(13.2)$ & $p=0.17$ \\
\hline Breathlessness-anxiety (\%) & $5.9(8.2)$ & $5.2(9.6)$ & $p=0.78$ \\
\hline Maximal exercise & Athlete & Sedentary & \\
\hline Work rate $(\mathrm{W})^{\star}$ & 325.0 (59.5) & $173.8(45.5)$ & $p<0.001^{*}$ \\
\hline$\dot{\mathrm{V}} \mathrm{O}_{2 \text { peak }}(\mathrm{mL} / \mathrm{kg} / \mathrm{min})^{*}$ & $50.8(7.3)$ & $31.6(7.4)$ & $p<0.001^{*}$ \\
\hline$\dot{\mathrm{V}}_{\mathrm{E}}(\llcorner/ \mathrm{min})$ & $146.4(37.0)$ & $77.8(27.0)$ & $p<0.001^{*}$ \\
\hline$\dot{\mathrm{V}}_{\mathrm{E}}(\% \text { above baseline })^{*}$ & 1051.7 (276.0) & $665.7(298.2)$ & $p<0.001^{*}$ \\
\hline$\dot{\mathrm{V}}_{\mathrm{E}}(\% \mathrm{MW})^{*}$ & $101.6(27.2)$ & $73.7(30.1)$ & $p=0.03^{\star}$ \\
\hline Breathlessness intensity (\%) & $80.7(22.7)$ & $72.5(16.4)$ & $p=0.21$ \\
\hline Breathlessness-anxiety (\%) & 45.3 (36.3) & $22.3(20.6)$ & $p=0.02^{*}$ \\
\hline
\end{tabular}

$\dot{V} \mathrm{O}_{2}$, volume of oxygen consumed; $\dot{V}_{E}$, ventilation; $M V$, maximal voluntary ventilation. *Significantly different $(p<0.05)$ between groups.

\section{Breathlessness Response to Chemostimulated Ventilation}

Mean group values for end-tidal gases, ventilation and subjective ratings of breathlessness during rest and the two steps of the hypercapnic challenge are presented in Table 3. Ventilation is presented as both an absolute value and percentage change from baseline (Table 1). No mean differences were observed between groups for subjective ratings of either intensity and anxiety of breathlessness at both levels of hypercapnia, and $\mathrm{P}_{E T} \mathrm{O}_{2}$ remained stable across the entire experiment in both groups.

Hypercapnic ventilatory response (HCVR) was calculated using a linear regression between ventilation and $\mathrm{P}_{\mathrm{ET}} \mathrm{CO}_{2}$, and no difference was found between the groups (mean $\pm \mathrm{SD}$ ): athletes 13.7 (9.6) vs. sedentary 14.0 (7.4) (l/min/\% change in $\mathrm{CO}_{2}$ ). For visual representation of individual subject HCVR see Supplementary Figure 1.

As the hypercapnic ventilatory response did not differ between the two groups, and there was no relationship between HCVR and either breathlessness intensity or anxiety $(P>0.05)$, we were then able to investigate the relationship between isolated changes in ventilation and the corresponding anxiety/intensity scores. During both mild and moderate hypercapnia, the athlete group showed a positive linear correlation for both intensity and anxiety with ventilation (mild hypercapnia: intensity vs. ventilation: slope $=5.41 ; r=0.79 ; p<0.05$; anxiety vs. ventilation: slope $=4.21 ; r=0.70 ; p<0.05$; moderate hypercapnia: intensity vs. ventilation: slope $=3.52 ; r=0.64$; $p<0.05$; anxiety vs. ventilation: slope $=3.10 ; r=0.59 ; p<$ 0.05 ), while the sedentary group did not (mild hypercapnia: intensity vs. ventilation: slope $=1.75 ; r=0.38 ; p>0.05$; anxiety vs. ventilation: slope $=-0.25 ; r=0.06 ; p>0.05$; moderate

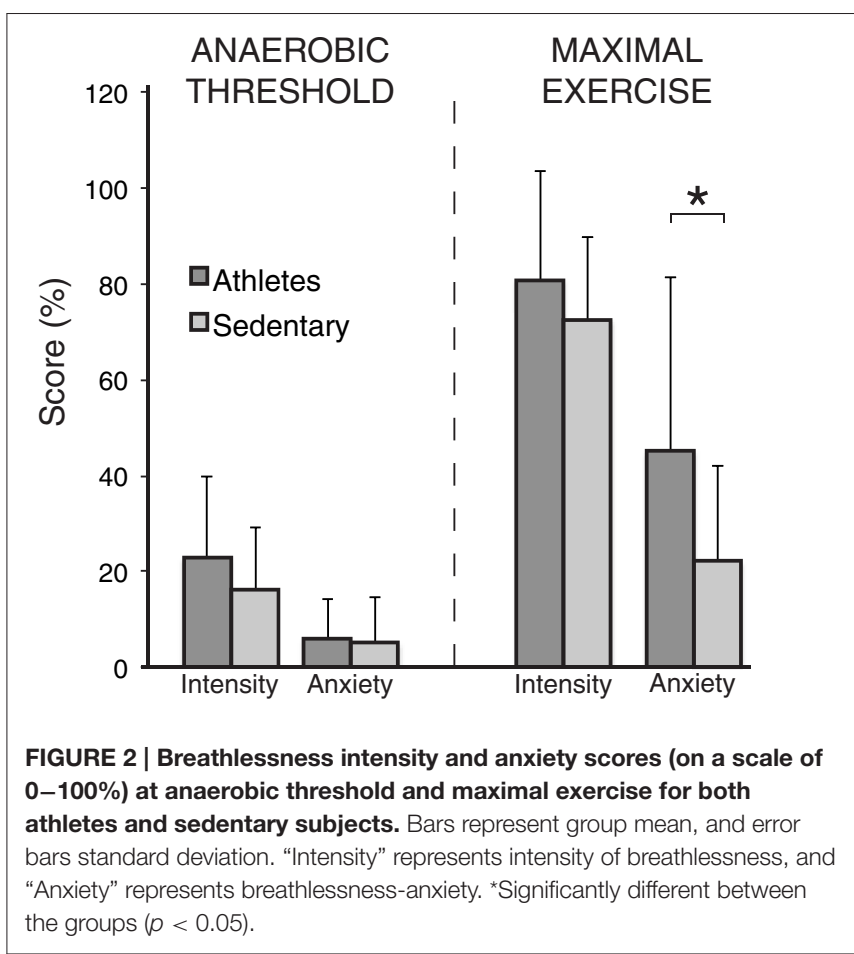

hypercapnia: intensity vs. ventilation: slope $=2.00 ; r=0.43$; $p>0.05$; anxiety vs. ventilation: slope $=-0.45 ; r=0.11$; $p>0.05)$. These linear correlations with ventilation observed in athletes were significantly greater than sedentary subjects for both intensity and anxiety in moderate hypercapnia, and for anxiety only in mild hypercapnia (Figure 4; Supplementary Table 1).

\section{DISCUSSION}

\section{Main Findings}

In this pilot study, we found that athletes reported increased anxiety of breathlessness compared to sedentary subjects at maximal exercise, while breathlessness intensity was rated at a similar level between the groups. Correspondingly, athletes were also found to be operating at a greater percentage of their MVV at maximal exercise. During a hypercapnic ventilatory response test, we found that athletes' breathlessness scores more accurately matched ventilation.

\section{Breathlessness and Exercise}

By separately assessing breathlessness intensity and anxiety, we can begin to disentangle the effects of sensory and affective components of breathlessness during exercise. While previous studies examining exercising breathlessness have used a Borg or modified Borg scales for breathlessness (El-Manshawi et al., 1986; Hamilton et al., 1996; Borg et al., 2010), this scale disregards the affective component of breathlessness, which is known to be important in clinical populations (Lansing et al., 2009; Herigstad et al., 2011, 2015, 2016; Janssens et al., 2011; Hayen et al., 2013). Interestingly, the increase in breathlessness-anxiety was not apparent at anaerobic threshold in athletes, indicating that this is 


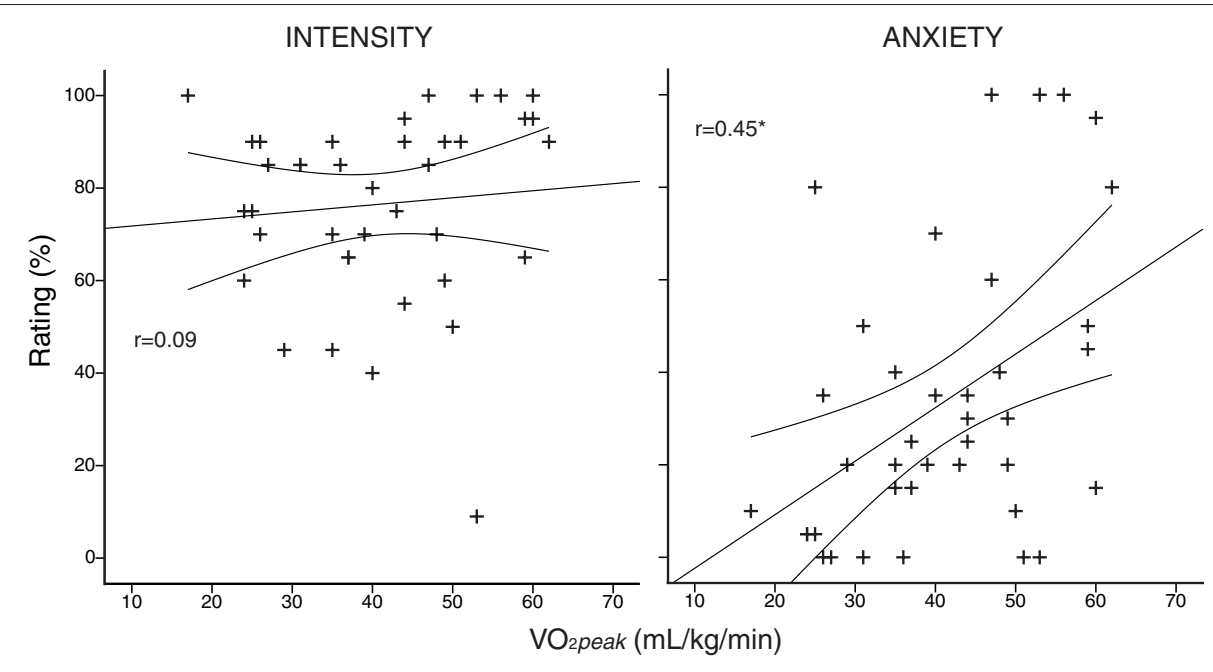

FIGURE 3 | Subject-specific anxiety and intensity scores plotted against peak volume of oxygen consumption $\left(\dot{V}^{2} \mathrm{O}_{2 \mathrm{peak}}\right)$, measured during an incremental exercise test to exhaustion on a stationary bicycle. Intensity of breathlessness is plotted in the left column, and anxiety of breathlessness in the right column. ${ }^{*} r$ correlation coefficient significant $(p<0.05)$. Curved lines represent $95 \%$ confidence intervals of the regression.

not a general breathlessness hypersensitivity, but rather limited to maximal efforts. Correspondingly, the ventilation reached during maximal exercise in athletes was a significantly greater proportion of measured MVV than sedentary subjects. This may be due to improved muscular metabolism and exercising capacity to place greater demands on the cardiorespiratory system, as this was also paired with a significantly greater increase in ventilation in the athlete group. Therefore, reaching a higher proportion of MVV may result in conflicting feedback between a greater drive to breathe and the strain of ventilatory muscle work (Schwartzstein et al., 1989; Waldrop et al., 1996; Kaufman and Forster, 1996), contributing to an increase in breathlessnessanxiety (Altose, 1985).

\section{Performance Implications}

While it is now known that mechanical limitations of the lungs and respiratory muscles can be reached in elite athletes during exercise (Dempsey et al., 1984; Powers et al., 1988; Johnson et al., 1992), and that respiratory muscle work can indirectly impede performance (Harms et al., 1997, 2000), perceptions of leg fatigue have previously been considered more important than breathlessness during maximal exercise (Borg et al., 2010). However, the effect of the emotional component of breathlessness on performance is not often considered. While the breathlessness-anxiety scores reported in this study were lower than those of breathlessness intensity, breathlessness-anxiety scores were found to correlate with $\dot{\mathrm{VO}}_{2 \text { peak }}$ across all subjects (Figure 3). Therefore, it is possible that breathlessness-anxiety may become a greater influence on performance in athletes with greater aerobic capacities than those tested in the current study.

Alternatively, the broad range of breathlessness-anxiety scores reported at maximal exercise may represent individuals who are more or less susceptible to affective breathlessness-anxiety, and a subset of athletes for whom breathing perception may play an important role in performance. It is possible that athletes who are genetically endowed with lower respiratory muscle endurance, or a higher sensitivity to ventilatory signals are also at risk of breathlessness-anxiety limiting their performance. Further research into the brain processing of sensory and affective components of breathlessness within the sensorimotor and limbic systems of the brain (Faull et al., 2015, 2016), together with ventilatory physiology is needed to better understand the underlying mechanisms of exercising breathlessness intensity and anxiety. It is also possible that psychophysiological interventions focused on reducing the impact of breathlessness-anxiety on performance may be advantageous to those susceptible athletes (reviewed by Gardner and Moore, 2004). Therefore, while debate thrives as to whether peripheral or central factors limit exercise performance (Bassett and Howley, 2000), we have revealed a potential place for breathlessness-anxiety in highly-trained, susceptible individuals. While we are not suggesting that anxiety of breathlessness is the sole limiting factor to performance, it may be an indicator of nearing ventilatory capacity and a possible area for targeted improvement in predisposed athletes.

\section{Breathlessness and Chemostimulated Ventilation}

Although we did not find group differences in ventilatory response or breathlessness scores during hypercapnia stimulated ventilation, further investigation revealed that in the athlete group breathlessness scores positively correlated with the change in ventilation, which was not observed in the sedentary subject group. This relationship between the physiological change in ventilation and subjective breathlessness implies a more finely-tuned perception of breathing changes in athletes. The differences in interoception may result from repeated exposure to elevated ventilation and breathlessness during endurance 
TABLE 3 | Physiological and psychological variables during rest and two levels of a hypercapnic hyperventilatory challenge (mild hypercapnia: aim of $0.8 \%$ (6.1 $\mathrm{mm} \mathrm{Hg})$; and moderate hypercapnia: aim of $1.5 \%(11.2 \mathrm{~mm}$ $\mathrm{Hg}$ ) increase in $\mathrm{PET}_{E T} \mathrm{CO}_{2}$; mean $\pm \mathrm{SD}$ ).

\begin{tabular}{|c|c|c|c|}
\hline Rest & Athlete & Sedentary & \\
\hline $\mathrm{P}_{\mathrm{ET}} \mathrm{CO}_{2}(\mathrm{mmHg})$ & $38.9(5.1)$ & $40.1(3.5)$ & $p=0.39$ \\
\hline $\mathrm{P}_{\mathrm{ET}} \mathrm{O}_{2}(\mathrm{mmHg})$ & $116.3(7.7)$ & $115.7(6.5)$ & $p=0.79$ \\
\hline$\dot{\mathrm{V}}_{\mathrm{E}}(1 / \mathrm{min})$ & $13.0(3.6)$ & $10.5(2.5)$ & $p=0.01^{*}$ \\
\hline Intensity rating (\%) & $3.1(4.5)$ & $4.6(3.8)$ & $p=0.25$ \\
\hline Anxiety rating (\%) & $3.1(4.1)$ & $5.1(5.1)$ & $p=0.17$ \\
\hline Mild hypercapnia & Athlete & Sedentary & \\
\hline $\mathrm{P}_{\mathrm{ET}} \mathrm{CO}_{2}(\mathrm{mmHg})$ & $46.0(4.7)$ & $46.5(3.0)$ & $p=0.67$ \\
\hline $\mathrm{P}_{\mathrm{ET}} \mathrm{O}_{2}(\mathrm{mmHg})$ & $114.7(5.6)$ & $115.8(4.6)$ & $p=0.49$ \\
\hline$\dot{V}_{E}(1 / m i n)$ & $23.3(10.2)$ & $20.6(4.8)$ & $p=0.30$ \\
\hline Change in $\dot{V}_{E}(\%)$ & $87.2(84.7)$ & $104.3(58.5)$ & $p=0.46$ \\
\hline Intensity rating (\%) & $26.0(20.2)$ & $21.9(15.5)$ & $p=0.48$ \\
\hline Anxiety rating (\%) & $18.9(17.9)$ & $17.2(13.9)$ & $p=0.74$ \\
\hline Moderate hypercapnia & Athlete & Sedentary & \\
\hline $\mathrm{P}_{\mathrm{ET}} \mathrm{CO}_{2}(\mathrm{mmHg})$ & $50.6(4.8)$ & $51.2(3.3)$ & $p=0.63$ \\
\hline $\mathrm{P}_{\mathrm{ET}} \mathrm{O}_{2}(\mathrm{mmHg})$ & $115.9(4.6)$ & $117.6(6.0)$ & $p=0.32$ \\
\hline$\dot{V}_{E}(1 / m i n)$ & $34.0(14.6)$ & $31.1(11.4)$ & $p=0.49$ \\
\hline Change in $\dot{V}_{E}(\%)$ & $174.4(115.4)$ & $205.6(121.4)$ & $p=0.41$ \\
\hline Intensity rating (\%) & $41.9(24.4)$ & $47.8(12.4)$ & $p=0.34$ \\
\hline Anxiety rating (\%) & $36.5(25.8)$ & $32.3(16.2)$ & $p=0.54$ \\
\hline
\end{tabular}

The order of hypercapnia levels was randomized between subjects, and results are presented as mean $\pm S D \cdot \dot{V}_{2}$, volume of oxygen consumed; $\dot{V}_{E}$, ventilation; MVV, maximal voluntary ventilation. ${ }^{*}$ Significantly different $(p<0.05)$ between groups.

exercise training, and could potentially contribute to the elevated anxiety at maximal exercise demonstrated by athletes, as athletes may be more acutely aware of their ventilatory work approaching maximal capacity.

\section{Performance Implications for Athletes}

The closer matching of ventilatory responses to breathlessness in athletes found in this study may reflect better monitoring of exercise intensity and pacing during sporting performance. Fatigue of ventilatory muscles has been suggested as an important factor in endurance exercise, due to the competition for blood and metabolites with the working peripheral muscles (Johnson et al., 1996; Harms et al., 2000; Romer and Polkey, 2008), and thus appropriate pacing may reduce this impact on performance. Further studies on ventilatory interoception (e.g., adapted from those employed in cardiovascular interoception; Garfinkel et al., 2015) in athletes may help us to better understand these psychological contributions to performance.

\section{Clinical Implications}

The results of this study may also help us to speculate more deeply on the mechanisms of breathlessness in clinical populations. It is well-recognized that people who suffer breathlessness may have altered perception of their breathing (Giardino et al., 2010). Due to the learned associations between breathlessness and

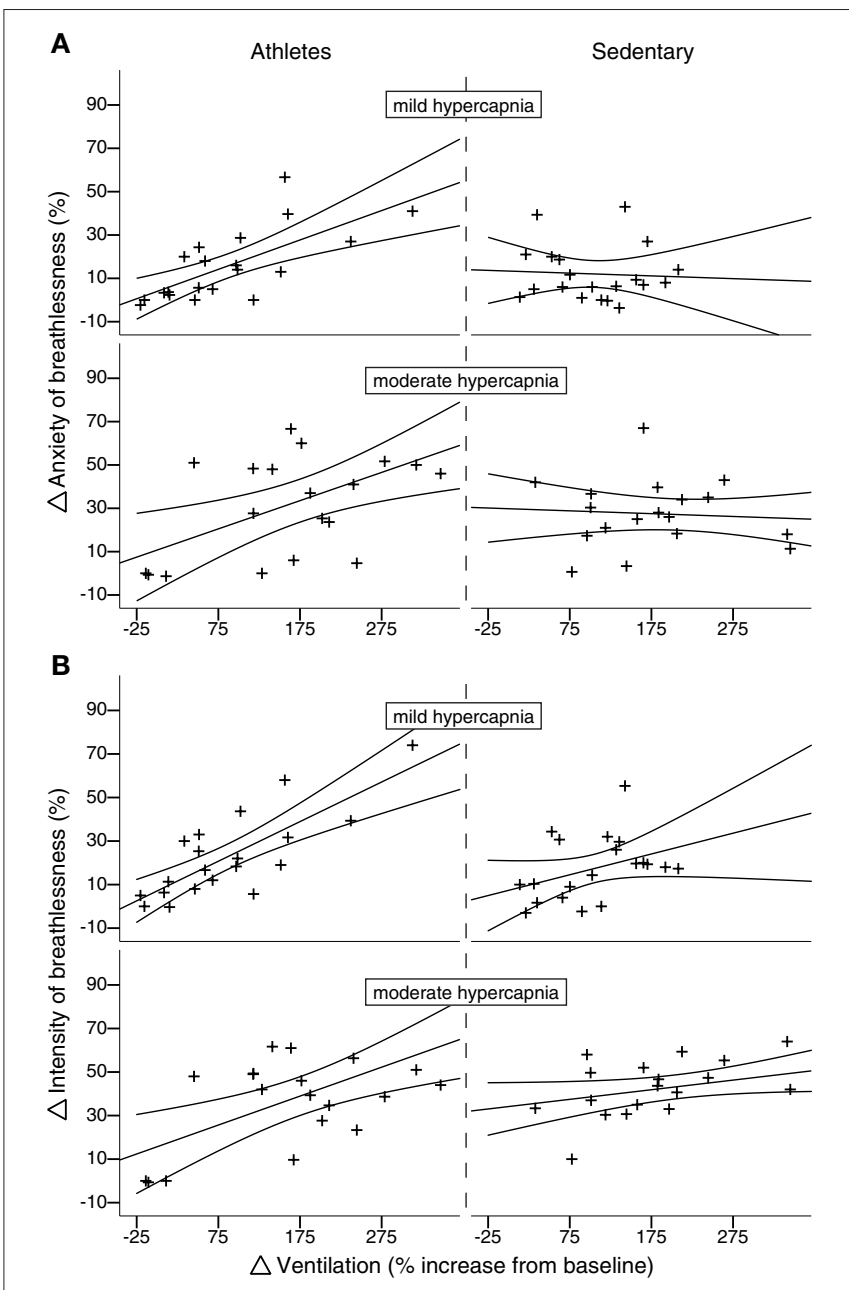

FIGURE 4 | Subject-specific change in breathlessness-anxiety (A) and intensity $(B)$ scores plotted against percentage change in ventilation from baseline induced by both mild and moderate hypercapnia (mild hypercapnia: aim of $0.8 \%$; and moderate hypercapnia: aim of $1.5 \%$ increase in $\mathbf{P}_{\mathrm{ET}} \mathbf{O}_{2}$ ). Athletes are plotted in the left column, and sedentary subjects in the right column. For moderate (but not mild) hypercapnia, athletes display a linear correlation between change in ventilation and change in intensity score that significantly differs from the null relationship seen in sedentary subjects. Ninety five percent confidence intervals are shown.

disease, maladaptive learning may then contribute to increased breathlessness-anxiety (Ley, 1999). It is thought that through repeated exposure to breathlessness, those with respiratory disease begin to fear and avoid activities that may induce this sensation, resulting in further deterioration of the ventilatory muscles in the chest and further reduction in MVV (Herigstad et al., 2011; Hayen et al., 2013). In an elegant review by Smoller et al. (1996), the intricacy of the relationship between physiological and subjective sensations of ventilation in panic anxiety, hyperventilation and breathlessness is outlined. Smoller et al. (1996) explains that the presence of chronic breathlessness can be considered a risk factor for anxiety and panic attacks, while panic disorder patients also report debilitating sensations of breathlessness that exacerbate their anxiety (Smoller et al., 
1996). It is therefore possible that an inappropriately tuned perception toward ventilation (as seen in athletes) due to repeated breathlessness exposure is a common contributing factor to these classes of disease.

\section{Study Design}

Due to the underlying physiological differences between athletes and sedentary subjects investigated in this study, considerations were taken to account for fundamental differences between the groups when attempting to make breathlessness comparisons. The exercising timepoints used for comparisons were maximal exercise and anaerobic threshold, with these comparable relative exercise intensities providing a more consistent platform from which to examine perceptual differences in breathlessness.

This pilot study is one of the first to consider perceptions of both breathlessness intensity and breathlessness-anxiety during exercise and hyrpercapnia-induced changes in ventilation in healthy individuals. The sample size of 40 subjects limits the generalisability of these findings, and further investigations involving greater numbers of subjects over a wide variety of training statuses would be highly beneficial for exploring the intricacies of how breathlessness perceptions may influence exercising performance.

\section{CONCLUSIONS}

This study showed that athletes report increased breathlessnessanxiety at maximal exercise compared to sedentary subjects, while intensity of breathlessness remains similar between the groups. We postulate that this may be related to athletes reaching a greater proportion of their maximal ventilatory capacity. While the intensity of perceived breathlessness has previously not been considered a contributor to maximal exercise, this affective dimension of breathlessness-anxiety may represent

\section{REFERENCES}

Aldrich, T. K., Arora, N. S., and Rochester, D. F. (1982). The influence of airwayobstruction and respiratory muscle strength on maximal voluntary ventilation in lung-disease. Am. Rev. Respir. Dis. 126, 195-199.

Altose, M. D. (1985). Assessment and management of breathlessness. Chest 88, 77S-83S. doi: 10.1378/chest.88.2_Supplement.77S

Banzett, R. B., Pedersen, S. H., Schwartzstein, R. M., and Lansing, R. W. (2008). The affective dimension of laboratory dyspnea. Am. J. Respir. Crit. Care Med. 177, 1384-1390. doi: 10.1164/rccm.200711-1675OC

Bassett, D. R., and Howley, E. T. (2000). Limiting factors for maximum oxygen uptake and determinants of endurance performance. Med. Sci. Sports Exerc. 32, 70-84. doi: 10.1097/00005768-200001000-00012

Bayulkem, K., and Lopez, G. (2010). Nonmotor fluctuations in Parkinson's disease: clinical spectrum and classification. J. Neurol. Sci. 289, 89-92. doi: 10.1016/j.jns.2009.08.022

Beaver, W. L., Wasserman, K., and Whipp, B. J. (1986). A new method for detecting anaerobic threshold by gas-exchange. J Appl Physiol 60, 2020-2027.

Borg, E., Borg, G., Larsson, K., Letzter, M., and Sundblad, B. M. (2010). An index for breathlessness and leg fatigue. Scand. J. Med. Sci. Sports 20, 644-650. doi: 10.1111/j.1600-0838.2009.00985.x

Carrieri-Kohlman, V., Donesky-Cuenco, D., Park, S. K., Mackin, L., Nguyen, H. Q., and Paul, S. (2010). Additional evidence for the affective dimension of dyspnea in patients with COPD. Res. Nurs. Health 33, 4-19. doi: 10.1002/nur.20359 both a performance limitation and a clinically important homeostatic signaling system for exercising breathlessness in susceptible, highly-trained individuals. Furthermore, we propose that the significantly different, more linear relationship between changes in ventilation and subjective breathlessness scores in athletes compared to sedentary subjects represents differences in ventilatory perception, which may also contribute to the increased breathlessness-anxiety reported at maximal exercise.

\section{AUTHOR CONTRIBUTIONS}

$\mathrm{OF}$ and PC were involved in the experimental design, data collection and manuscript preparation. KP is the senior author and was involved in study design and manuscript preparation.

\section{ACKNOWLEDGMENTS}

This research was supported by the JABBS Foundation, a registered UK charity. This research was further supported by the National Institute for Health Research, Oxford Biomedical Research Centre based at Oxford University Hospitals NHS Trust and University of Oxford. KP was supported by an MRC Clinician Scientist Fellowship. OF was supported by the Commonwealth Scholarship Commission. The authors would like to thank Dr. Sam J. E. Lucas for his comments and contributions to the paper. The results of the present study do not constitute endorsement by ACSM.

\section{SUPPLEMENTARY MATERIAL}

The Supplementary Material for this article can be found online at: http://journal.frontiersin.org/article/10.3389/fphys. 2016.00231
Carrieri-Kohlman, V., Gormley, J. M., Eiser, S., Demir-Deviren, S., Nguyen, H., Paul, S. M., et al. (2001). Dyspnea and the affective response during exercise training in obstructive pulmonary disease. Nurs. Res. 50, 136-146. doi: 10.1097/00006199-200105000-00002

Cohen, J. (1992). A power primer. Psychol. Bull. 112:155. doi: 10.1037/00332909.112.1.155

Dempsey, J. A., Hanson, P. G., and Henderson, K. S. (1984). Exercise-induced arterial hypoxaemia in healthy human subjects at sea level. J. Physiol. 355, 161-175. doi: 10.1113/jphysiol.1984.sp015412

El-Manshawi, A., Killian, K. J., Summers, E., and Jones, N. L. (1986). Breathlessness during exercise with and without resistive loading. J. Appl. Physiol. 61, 896-905.

Ezra, M., Faull, O. K., Jbabdi, S., and Pattinson, K. T. (2015). Connectivitybased segmentation of the periaqueductal gray matter in human with brainstem optimized diffusion MRI. Hum. Brain Mapp. 36, 3459-3471. doi: 10.1002/hbm. 22855

Faull, O. K., Jenkinson, M., Clare, S., and Pattinson, K. T. (2015). Functional subdivision of the human periaqueductal grey in respiratory control using Tesla fMRI. Neuroimage 113, 356-364. doi: 10.1016/j.neuroimage.2015.02.026

Faull, O. K., Jenkinson, M., Ezra, M., and Pattinson, K. T. (2016). Conditioned respiratory threat in the subdivisions of the human periaqueductal gray. Elife 5:e12047. doi: 10.7554/eLife.12047

Gardner, F. L., and Moore, Z. E. (2004). A mindfulness-acceptance-commitmentbased approach to athletic performance enhancement: theoretical considerations. Behav. Ther. 35, 707-723. doi: 10.1016/S0005-7894(04)80016-9 
Garfinkel, S. N., Seth, A. K., Barrett, A. B., Suzuki, K., and Critchley, H. D. (2015). Knowing your own heart: distinguishing interoceptive accuracy from interoceptive awareness. Biol. Psychol. 104, 65-74. doi: 10.1016/j.biopsycho.2014.11.004

Georges, M., Moraviec, E., Raux, M., Gonzalez-Bermejo, J., Pradat, P. F., Similowski, T., et al. (2016). Cortical drive to breathe in amyotrophic lateral sclerosis: a dyspnoea-worsening defence? Eur. Respir. J. 47, 1818-1828. doi: 10.1183/13993003.01686-2015

Giardino, N. D., Curtis, J. L., Abelson, J. L., King, A. P., Pamp, B., Liberzon, I., et al. (2010). The impact of panic disorder on interoception and dyspnea reports in chronic obstructive pulmonary disease. Biol. Psychol. 84, 142-146. doi: 10.1016/j.biopsycho.2010.02.007

Hamilton, A. L., Killian, K. J., Summers, E., and Jones, N. L. (1996). Quantification of intensity of sensations during muscular work by normal subjects. J. Appl. Physiol. 81, 1156-1161.

Harms, C. A., Babcock, M. A., McClaran, S. R., Pegelow, D. F., Nickele, G. A., Nelson, W. B., et al. (1997). Respiratory muscle work compromises leg blood flow during maximal exercise. J. Appl. Physiol. 82, 1573-1583.

Harms, C. A., Wetter, T. J., St Croix, C. M., Pegelow, D. F., and Dempsey, J. A. (2000). Effects of respiratory muscle work on exercise performance. J. Appl. Physiol. 89, 131-138.

Hayen, A., Herigstad, M., and Pattinson, K. T. S. (2013). Understanding dyspnea as a complex individual experience. Maturitas 76, 45-50. doi: 10.1016/j.maturitas.2013.06.005

Herigstad, M., Hayen, A., Evans, E., Hardinge, F. M., Davies, R. J., Wiech, K., et al. (2015). Dyspnea-related cues engage the prefrontal cortex. Chest 148, 953-961. doi: $10.1378 /$ chest.15-0416

Herigstad, M., Hayen, A., Reinecke, A., and Pattinson, K. T. (2016). Development of a dyspnoea word cue set for studies of emotional processing in COPD. Respir. Physiol. Neurobiol. 223, 37-42. doi: 10.1016/j.resp.2015. 12.006

Herigstad, M., Hayen, A., Wiech, K., and Pattinson, K. T. S. (2011). Dyspnoea and the brain. Respir. Med. 105, 809-817. doi: 10.1016/j.rmed.2010.1 2.022

Janssens, T., De Peuter, S., Stans, L., Verleden, G., Troosters, T., Decramer, M., et al. (2011). Dyspnea perception in COPD: association between anxiety, dyspnearelated fear, and dyspnea in a pulmonary rehabilitation program. Chest 140, 618-625. doi: 10.1378/chest.10-3257

Johnson, B. D., Aaron, E. A., Babcock, M. A., and Dempsey, J. A. (1996). Respiratory muscle fatigue during exercise: implications for performance. Med. Sci. Sports Exerc. 28, 1129-1137. doi: 10.1097/00005768-19960900 0-00008

Johnson, B. D., Saupe, K. W., and Dempsey, J. A. (1992). Mechanical constraints on exercise hyperpnea in endurance athletes. J. Appl. Physiol. 73, 874-886.

Jones, P. W. (2001). Health status measurement in chronic obstructive pulmonary disease. Thorax 56, 880-887. doi: 10.1136/thorax.56.11.880

Kaufman, M. P., and Forster, H. V. (1996). Reflexes controlling circulatory, ventilatory and airway responses to exercise. Comprehensive Physiology Supplement 29: Handbook of Physiology, Exercise: Regulation and Integration of Multiple Systems, eds L. B. Rowell and J. T. Shepherd (New York, NY: Oxford University Press), 381-447.

Lansing, R. W., Gracely, R. H., and Banzett, R. B. (2009). The multiple dimensions of dyspnea: review and hypotheses. Respir. Physiol. Neurobiol. 167, 53-60. doi: 10.1016/j.resp.2008.07.012

Lansing, R. W., Im, B., Thwing, J. I., Legedza, A., and Banzett, R. B. (2000). The perception of respiratory work and effort can be independent of the perception of air hunger. Am. J. Respir. Crit. Care Med. 162, 1690-1696. doi: 10.1164/ajrccm.162.5.9907096

Laviolette, L., and Laveneziana, P. (2014). Dyspnoea: a multidimensional and multidisciplinary approach. Eur. Respir. J. 43, 1750-1762. doi: $10.1183 / 09031936.00092613$

Levy, M. L., Quanjer, P. H., Rachel, B., Cooper, B. G., Holmes, S., and Small, I. R. (2009). Diagnostic spirometry in primary care. Prim. Care Respir. J. 18, 130-147. doi: 10.4104/pcrj.2009.00054

Ley, R. (1999). The modification of breathing behavior pavlovian and operant control in emotion and cognition. Behav. Mod. 23, 441-479. doi: 10.1177/0145445599233006

McArdle, W. D., Katch, F. I., and Katch, V. L. (2006). Essentials of Exercise Physiology. Baltimore, MD; Philadelphia, PA: Lippincott Williams \& Wilkins.
McLaughlin, J. E., King, G. A., Howley, E. T., Bassett D. R. Jr., and Ainsworth, B. E. (2001). Validation of the COSMED K4 b2 portable metabolic system. Int. J. Sports Med. 22, 280-284. doi: 10.1055/s-2001-13816

Mutluay, F. K., Gürses, H. N., and Saip, S. (2005). Effects of multiple sclerosis on respiratory functions. Clin. Rehabil. 19, 426-432. doi: 10.1191/0269215505cr782oa

Pattinson, K. T., and Turner, M. R. (2016). A wider pathological network underlying breathlessness and respiratory failure in amyotrophic lateral sclerosis. Eur. Respir. J. 47, 1632-1634. doi: 10.1183/13993003.00321-2016

Powers, S. K., Dodd, S., Lawler, J., Landry, G., Kirtley, M., McKnight, T., et al. (1988). Incidence of exercise induced hypoxemia in elite endurance athletes at sea-level. Eur. J. Appl. Physiol. Occup. Physiol. 58, 298-302. doi: $10.1007 / \mathrm{BF} 00417266$

Radloff, L. S. (1977). The CES-D scale a self-report depression scale for research in the general population. Appl. Psychol. Meas. 1, 385-401. doi: $10.1177 / 014662167700100306$

Reiss, S., Peterson, R. A., Gursky, D. M., and McNally, R. J. (1986). Anxiety sensitivity, anxiety frequency and the prediction of fearfulness. Behav. Res. Ther. 24, 1-8. doi: 10.1016/0005-7967(86)90143-9

Romer, L. M., and Polkey, M. I. (2008). Exercise-induced respiratory muscle fatigue: implications for performance. J. Appl. Physiol. 104, 879-888. doi: 10.1152/japplphysiol.01157.2007

Schwartzstein, R. M., Manning, H. L., Weiss, J. W., and Weinberger, S. E. (1990). Dyspnea - a sensory experience. Lung 168, 185-199. doi: 10.1007/BF02719692

Schwartzstein, R. M., Simon, P. M., Weiss, J. W., Fencl, V., and Weinberger S. E. (1989). Breathlessness Induced by dissociation between ventilation and chemical drive. Am. Rev. Respir. Dis. 139, 1231-1237. doi: 10.1164/ajrccm/139.5.1231

Simon, P. M., Schwartzstein, R. M., Weiss, J. W., Lahive, K., Fencl, V. Teghtsoonian, M., et al. (1989). Distinguishable sensations of breathlessness induced in normal volunteers. Am. Rev. Respir. Dis. 140, 1021-1027. doi: 10.1164/ajrccm/140.4.1021

Sivak, E. D., Shefner, J. M., and Sexton, J. (1999). Neuromuscular disease and hypoventilation. Curr. Opin. Pulm. Med. 5, 355-362. doi: 10.1097/00063198199911000-00006

Smoller, J. W., Pollack, M. H., Otto, M. W., Rosenbaum, J. F., and Kradin, R. L. (1996). Panic anxiety, dyspnea, and respiratory disease: theoretical and clinical considerations. Am. J. Respir. Crit. Care Med. 154, 6-17. doi: 10.1164/ajrccm.154.1.8680700

Solano, J. P., Gomes, B., and Higginson, I. J. (2006). A comparison of symptom prevalence in far advanced cancer, AIDS, heart disease, chronic obstructive pulmonary disease and renal disease. J. Pain Symptom Manage. 31, 58-69. doi: 10.1016/j.jpainsymman.2005.06.007

Spielberger, C. D. (2010). State-Trait Anxiety Inventory. Corsini Encyclopedia of Psychology. Hoboken, NJ: John Wiley and Sons, Inc.

von Leupoldt, A., and Dahme, B. (2005). Differentiation between the sensory and affective dimension of dyspnea during resistive load breathing in normal subjects. Chest 128, 3345-3349. doi: 10.1378/chest.128.5.3345

Waldrop, T. G., Eldridge, F. L., Iwamoto, G. A., and Mitchell, J. H. (1996). “Central neural control of respiration and circulation during exercise," in Comprehensive Physiology Supplement 29: Handbook of Physiology, Exercise: Regulation and Integration of Multiple Systems, eds L. B. Rowell and J. T. Shepherd (New York, NY: Oxford University Press), 333-380.

Wasserman, K., Van Kessel, A. L., and Burton, G. G. (1967). Interaction of physiological mechanisms during exercise. J. Appl. Physiol. 22, 71-85.

Wasserman, K., Whipp, B. J., Koyal, S. N., and Beaver, W. L. (1973). Anaerobic threshold and respiratory gas-exchange during exercise. J. Appl. Physiol. 35, 236-243.

Conflict of Interest Statement: The authors declare that the research was conducted in the absence of any commercial or financial relationships that could be construed as a potential conflict of interest.

Copyright (c) 2016 Faull, Cox and Pattinson. This is an open-access article distributed under the terms of the Creative Commons Attribution License (CC BY). The use, distribution or reproduction in other forums is permitted, provided the original author(s) or licensor are credited and that the original publication in this journal is cited, in accordance with accepted academic practice. No use, distribution or reproduction is permitted which does not comply with these terms. 